\begin{abstract}
HHS Public Access
Author manuscript

Curr Heart Fail Rep. Author manuscript; available in PMC 2015 June 15.

Published in final edited form as:

Curr Heart Fail Rep. 2013 December ; 10(4): 341-349. doi:10.1007/s11897-013-0166-4.

\section{Ventricular Remodeling in Heart Failure with Preserved Ejection Fraction}

\author{
Amil M. Shah, MD, MPH \\ Division of Cardiovascular Medicine, Brigham and Women's Hospital, Boston, MA, USA
}

Abstract

Heart failure with preserved ejection fraction (HFpEF) is common, increasing in prevalence, and causes substantial morbidity and mortality. HFpEF has commonly been viewed as an expression of advanced hypertensive heart disease, with a cardiac phenotype characterized by an increase in wall thickness-to-chamber radius ratio (concentric hypertrophy). However, marked clinical heterogeneity within this syndrome is now well appreciated, and is mirrored in the variability in left ventricular structure. A review of larger imaging studies from epidemiology and clinical trial cohorts demonstrate that while concentric LV remodeling is common, it is by no means universal and many patients demonstrate normal LV geometry or even an eccentric pattern. More detailed assessment of cardiac structure and function in broader HFpEF populations will be necessary to better define the prevalence, determinants, and prognostic relevance of these measures, which may in turn serve as a foundation to identify pathophysiologically relevant sub-phenotypes within this diverse syndrome.
\end{abstract}

\title{
Keywords
}

Heart failure; Preserved Ejection Fraction; Ventricular Remodeling; Echocardiography

\section{Introduction}

Data from community-based studies have established that heart failure with preserved ejection fraction (HFpEF) accounts for up to $50 \%$ of $\mathrm{HF}$ cases and is increasing in prevalence. ${ }^{1,2} \mathrm{HFpEF}$ is associated with rates of $\mathrm{HF}$ re-hospitalization and functional decline similar to $\mathrm{HF}$ with reduced $\mathrm{EF}(\mathrm{HFrEF}){ }^{3,4}$ and carries a significantly higher risk of death compared to age-matched controls. ${ }^{5,6}$ However, no disease-specific therapy exists to improve prognosis in this heterogeneous syndrome, despite multiple randomized controlled trials. ${ }^{7,8,9} \mathrm{HFpEF}$ has commonly been viewed as an expression of advanced hypertensive heart disease, with antecedent hypertension present in $60-90 \%$ of HFpEF cases in

\footnotetext{
Address for Correspondence: Amil M. Shah MD MPH, Division of Cardiovascular Medicine, Brigham and Women's Hospital, 75 Francis Street, Boston, MA 02115. Fax: 617-732-5291, Tel: 617-732-5681, ashah11@partners.org.

Conflict of Interest

Amil M. Shah declares that he has no conflict of interest.

Compliance with Ethics Guidelines

Human and Animal Rights and Informed Consent

This article does not contain any studies with human or animal subjects performed by any of the authors.
} 
epidemiologic studies. ${ }^{10,11}$ The fundamental association between myocardial wall stress, ventricular hypertrophy, and chamber enlargement was described decades ago. ${ }^{12,13} \mathrm{LV}$ shape, or geometry, can be described based on the LV mass (hypertrophy) and the relative wall thickness (RWT), which describes the relationship between wall thickness and cavity size (concentricity). LV hypertrophy can occur in the context of increased RWT (concentric hypertrophy) or normal to reduced RWT (eccentric hypertrophy). Increased concentricity can also occur in the absence of frank hypertrophy (concentric remodeling). In the context of hypertensive disease, sarcomere replication in parallel with associated increase in wall thickness-to-chamber radius ratio (concentric hypertrophy) would allow for normalization of LV peak systolic meridional wall stress, and would therefore be the expected pattern of remodeling in HFpEF. Supporting this model, several investigators have shown that HFpEF is associated with significantly increased LV wall thickness and reduced chamber dimension compared to healthy controls or hypertensive patients without HF. ${ }^{14,15}$ At the myocardial level, HFpEF patients demonstrate increased cardiomyocyte stiffness, elevated interstitial myocardial collagen content, and greater cardiomyocyte hypertrophy. ${ }^{16}$ Invasive hemodynamic studies of LV function in select HFpEF patients have demonstrated both impaired early diastolic active relaxation and increased passive stiffness. ${ }^{17,18}$

Although this model accurately accounts for some patients with HFpEF, marked clinical heterogeneity within this syndrome is now well appreciated. In particular, beyond hypertension, the contribution of co-existing coronary artery disease, atrial fibrillation, and pulmonary dysfunction are being increasingly recognized. ${ }^{19,20,21}$ Mechanistically, measures of diastolic function have performed poorly in discriminating HFpEF patients from their comorbidity matched symptom-free counterparts, ${ }^{22}$ are absent in approximately one-third of HFpEF patients, ${ }^{23,24}$ and fail to reliably predict adverse events in HFpEF. Simultaneously, numerous additional pathophysiologic abnormalities have been described in HFpEF, including impaired systolic function despite preserved $\mathrm{LVEF},{ }^{25,26}$ increased ventricular dyssynchrony, ${ }^{27,28}$ impaired left atrial function, ${ }^{29}$ pulmonary hypertension, ${ }^{30}$ increased arterial stiffness, ${ }^{31}$ and impaired peripheral oxygen extraction. ${ }^{32}$ Similar heterogeneity in cardiac structure and function in HFpEF is also being increasingly recognized. ${ }^{33}$ In prior studies, patient were often selected based on prior HF hospitalization and/or the presence of concentric structural remodeling which, together with limited sample size, may have limited the cardiac phenotype observed. ${ }^{14,15,34}$ In this review, we focus on larger imaging studies from epidemiology and clinical trial cohorts that included a broad population of HFpEF patients, in an attempt to capture the breadth of structural remodeling in $\mathrm{HFpEF}$ and mitigate the impact of inclusion bias.

\section{Assessment of Ventricular Structure in HFpEF}

While cardiac magnetic resonance imaging provides high resolution data on cardiac structure and complementary information on tissue characterization and fibrosis, ${ }^{35}$ echocardiography has been the most commonly employed imaging modality in these larger clinical studies. It is the least expensive imaging modality, safe, portable, and able to evaluate cardiac structure, systolic and diastolic function, valvular function, and hemodynamics. However, image acquisition and measurement techniques are operator dependent, and both can be sources of variability. Fortunately, many large clinical studies of 
HFpEF utilizing echocardiography have employed core laboratories to mitigate these sources of variability as recommended by professional societies, ${ }^{36}$ although inter-laboratory measurement differences remain a potential source of between-study differences in cardiac structure and function.

Epidemiologic cohort studies offer the least biased view of HFpEF in the community, but have been limited by relatively small numbers of incident HFpEF cases. Hospital-based HFpEF registries obviate many of the inclusion biases inherent in clinical trial populations, particularly with regards to inclusion of patients with advanced co-mordibities - such as chronic kidney disease - who are often excluded from therapeutic trials for safety reasons. However, referral bias remains a significant consideration, as frequently only those admitted with acute decompensation are enrolled. In addition, the uniform implementation, analysis, and reporting of cardiac structure and function in most large HF registries has been limited. Finally, imaging sub-studies of HFpEF clinical trials have the unique advantages of large numbers of cases, robust clinical phenotyping, and prospective assessments. By necessity, clinical trials impose inclusion and exclusion criteria, and in HFpEF trials these frequently include echocardiographic criteria.8,9,37 Therefore, these studies are clearly not reflective of HFpEF epidemiology, and identify specific subsets of patients within the HFpEF syndrome.

\section{Ventricular Remodeling in HFpEF in Epidemiologic Studies and Hospital Registries}

Across epidemiologic studies, mean LV size tends to be normal, with variable degrees of LV wall thickening (Table 1). One of the largest and most comprehensive epidemiologic evaluations of cardiac structure and function in HFpEF is the Olmsted County cohort. ${ }^{38}$ Among $244 \mathrm{HFpEF}$ cases, ventricular hypertrophy was present in $42 \%$ of participants. Interestingly, while concentric hypertrophy or remodeling was present in $53 \%$, eccentric hypertrophy was also noted in $16 \%$. In addition, LV geometry was normal in nearly onethird of HFpEF cases (31\%). The Cardiovascular Health Study, an older study of HFpEF cases of similar age and gender, demonstrated similar average LV mass index but somewhat larger ventricles with a lesser degree of concentric remodeling. ${ }^{39}$

The Northwestern HFpEF Registry provides perhaps the most comprehensive assessment to date of cardiac structure and function in a registry setting (Table 1), and demonstrated greater concentric remodeling and higher prevalence of LV hypertrophy than most epidemiologic studies. ${ }^{40}$ Interestingly, similar to the Olmsted County cohort, $12 \%$ of patients in this registry demonstrated an eccentric pattern of ventricular hypertrophy. This registry is also one of the few observational cohorts to report on left atrial remodeling and noted a high prevalence of left atrial enlargement with a mean LA volume index of 33.6 $\mathrm{ml} / \mathrm{m}^{2}$ (abnormal $>29 \mathrm{ml} / \mathrm{m}^{2}$ ).

\section{Ventricular Remodeling in HFpEF Clinical Trials}

In HFpEF clinical trial imaging sub-studies, mean LV size tends to be normal, although appreciable within trial and between trial variability exists (Table 2). Similarly, LV wall thickness also varies between trials, with trials requiring elevated wall thickness for 
inclusion demonstrating higher wall thickness and LV mass.8 As a result of these differences in chamber size and wall thickness, there is wide variability in the prevalence of both increased concentricity (wall thickness relative to chamber diameter) and LV hypertrophy, ranging from $14-49 \%$ and $21-59 \%$ respectively. Indeed, in the echocardiographic sub-study of the I-PRESERVE trial, the largest and most comprehensive study to date, nearly half (46\%) of the 745 patients in the sub-study demonstrated normal LV geometry. ${ }^{24}$ In addition, similar to the Olmsted County and Northwestern experiences, $7 \%$ of patients in the PARAMOUNT trial demonstrated an eccentric pattern of hypertrophy. ${ }^{41}$ Together, these observations highlight the marked heterogeneity of ventricular morphology found within this syndrome (Figure 1).

\section{Racial/Ethnic Variation in Cardiac Structure and Function in HFpEF}

Limited data is currently available regarding ethnic/racial variation in cardiac structure and function in HFpEF. Among Native Americans, the NHLBI Strong Heart Study suggests similar patterns of ventricular remodeling as observed in the Olmsted cohort. ${ }^{42}$ Data from the a relatively small Chinese referral cohort of HFpEF patients also suggests similar LV size and mass as observed in the Olmsted cohort, ${ }^{43}$ although the ongoing prospective PEOPLE/SHEP study should help further clarify the extent and magnitude of ventricular remodeling among Asians with HFpEF. ${ }^{44}$ Even less data is currently available in Hispanic populations.

A particularly important gap in our current understanding is the limited data available regarding cardiac structure and function among blacks, who carry a disproportionate share of the HF burden but are uniformly under-represented in clinical trials and most large epidemiologic cohort studies. Among U.S. cohorts, African Americans demonstrate particularly high $\mathrm{HF}$ prevalence ${ }^{45}$ and incidence, ${ }^{46}$ and experience higher mortality with HFpEF. ${ }^{47}$ Comparative studies in non-hypertensive healthy subjects suggest that LV mass and relative wall thickness are higher in African Americans compared to whites, ${ }^{48}$ and African Americans appear to develop greater degrees of diastolic dysfunction, ${ }^{49}$ concentric remodeling, ${ }^{50}$ and hypertrophy ${ }^{51}$ for a set degree of hypertension. Perhaps the most comprehensive data to date on cardiac structure and function among African Americans with HFpEF comes from the NHLBI Atherosclerosis Risk in Communities (ARIC) Study's Jackson, MS cohort. ${ }^{52}$ Among 2,445 African American participants, the 85 identified with HF tended to demonstrate smaller LV chambers, higher LV mass and relative wall thickness, and higher prevalence of concentric hypertrophy compared to other - albeit larger - cohort studies.

\section{Prognostic Relevance of Ventricular Remodeling in HFpEF}

The echocardiographic sub-study of the I-PRESERVE trial clearly demonstrated the prognostic relevance of LV hypertrophy for both all-cause mortality and HF mortality or hospitalization. ${ }^{24}$ Even after multivariable adjustment, the presence of LV hypertrophy was associated with a hazard ratio of 1.59 (95\% CI 1.17-2.16; $\mathrm{p}=0.003$ ) for mortality. Similarly, in the Northwestern HFpEF Registry, LV hypertrophy was associated with a significantly higher incidence of death or cardiovascular hospitalization, although in this study no 
significant difference in incidence rates was noted between those with a concentric pattern of hypertrophy compared to those with an eccentric pattern. ${ }^{40}$ Along with ventricular remodeling, I-PRESERVE also demonstrated the prognostic importance of atrial remodeling in HFpEF. Left atrial enlargement, likely a marker of LV diastolic dysfunction and chronically elevated filling pressure, ${ }^{53}$ was associated with a hazard ratio of 1.47 (95\% CI $1.03-2.10, \mathrm{p}=0.03$ ) for death in multivariable adjusted models. ${ }^{24}$ This finding contrasts with Doppler-based measures of diastolic function, which have only variably been associated with outcomes in HFpEF. ${ }^{23,24}$ Finally, data from the Olmsted cohort demonstrate the prognostic importance of pulmonary hypertension in $\mathrm{HFpEF}$, which appears at least partially - though not fully - related to LV diastolic dysfunction. ${ }^{30}$

\section{Future Directions}

\section{Relationship of Structural Remodeling to Functional Impairment in HFpEF}

The functional implications of LV structural remodeling in HFpEF are not well understood. Concentric remodeling has been associated with impaired diastolic function and increased diastolic LV stiffness. ${ }^{54}$ However, several studies also suggest that concentric remodeling can mask impairments in myocardial systolic function despite preserved or even increased chamber-level measures of LV systolic function, such as ejection fraction and fractional shortening. ${ }^{55,56,57}$ More recent data using 2D speckle tracking indicate that progressive concentric remodeling is associated with reduced longitudinal deformation despite normal LVEF and increased circumferential deformation. ${ }^{58}$ This emerging data using myocardial deformation imaging suggest a distinct pattern of LV dysfunction in conditions predisposing to HFpEF, such as hypertension and diabetes, characterized by impaired longitudinal systolic function with concomitant increase in circumferential systolic function, maintaining overall LVEF. ${ }^{59,60,61}$ However, the prevalence and independent prognostic relevance of impaired ventricular deformation despite preserved LVEF in HFpEF remain unclear.

\section{Right Ventricular Function and Pulmonary Vascular Disease in HFpEF}

Pulmonary hypertension is powerful risk factor for adverse outcomes in HFpEF. However, elevation in LV filling pressure does not appear able to fully account for pulmonary hypertension in $\mathrm{HFpEF}$ and concomitant elevations in pulmonary vascular resistance and pulmonary arterial stiffness have been suggested. ${ }^{30}$ Similarly, while this review has focused on structural alterations in the LV in $\mathrm{HFpEF}$, right ventricular dysfunction has demonstrated prognostic import in HF with reduced LVEF, LV dysfunction following myocardial infarction, and pulmonary arterial hypertension. ${ }^{62,63,64}$ However, little data to date exists regarding the prevalence, magnitude, and prognostic implications of both pulmonary vascular dysfunction and right ventricular dysfunction in HFpEF.

\section{Using Cardiac Structure and Function to Identify HFpEF Sub-phenotypes}

Phenotypic heterogeneity is now a well-recognized component of the HFpEF syndrome. A review of cardiac structure and function in HFpEF demonstrates similar diversity. While biases of study inclusion criteria and measurement variability contribute, this variability likely also reflects heterogeneity in underlying pathophysiology within this syndrome. Therefore, the ability to define sub-phenotypes within this heterogeneous syndrome may 
allow for more effective targeting of treatments for this syndrome for which there are currently no efficacious therapies. Integration of quantitative measures of cardiac structure and function - including structural remodeling, biventricular systolic and diastolic function, and systemic and pulmonary vascular function - offers a promising foundation for the identification of such sub-groups.

\section{Conclusions}

Patients with the HFpEF syndrome demonstrate diverse patterns of ventricular remodeling, likely mirroring the clinical and pathophysiologic heterogeneity of this syndrome. While concentric LV remodeling is common, it is by no means universal and many patients demonstrate normal LV geometry or even an eccentric pattern. More detailed assessment of cardiac structure and function in broader HFpEF populations will be necessary to better define the prevalence, determinants, and prognostic relevance of these measures. This 'deep phenotyping' of structure and function may eventually serve as a foundation to identify pathophysiologically relevant sub-phenotypes within HFpEF, and promote more effective targeting and testing of therapies to ultimately reduce disease burden.

\section{References}

1. Bhatia RS, Tu JV, Lee DS, Austin PC, Fang J, Haouzi A, Gong Y, Liu P. Outcome of heart failure with preserved ejection fraction in a population-based study. New Engl J Med. 2006; 355:260-9. [PubMed: 16855266]

2. Owan TE, Hodge DO, Herges RM, Jacobsen SJ, Roger VL, Redfield MM. Trends in prevalence and outcome of heart failure with preserved ejection fraction. New Engl J Med. 2006; 355:251-9. [PubMed: 16855265]

3. Tsutsui H, Tsuchihashi M, Takeshita A. Mortality and readmission of hospitalized patients with congestive heart failure and preserved versus depressed systolic function. Am J Cardiol. 2001; 88:530-3. [PubMed: 11524063]

4. Smith GL, Masoudi FA, Vaccarino V, Radford MJ, Krumholz HM. Outcomes in heart failure patients with preserved ejection fraction: mortality, readmission, and functional decline. J Am Coll Cardiol. 2003; 41:1510-8. [PubMed: 12742291]

5. Vasan RS, Larson MG, Benjamin EJ, Evans JC, Reiss CK, Levy D. Congestive heart failure in subjects with normal versus reduced left ventricular ejection fraction: prevalence and mortality in a population-based cohort. J Am Coll Cardiol. 1999; 33:1948-55. [PubMed: 10362198]

6. Davis BR, Kostis JB, Simpson LM, Black HR, Cushman WC, Einhorn PT, Farber MA, Ford CE, Levy D, Massie BM, Nawaz S. for the ALLHAT Collaborative Research Group. Heart failure with preserved and reduced left ventricular ejection fraction in the antihypertensive and lipid-lowering treatment to prevent heart attack trial. Circulation. 2008; 118:2259-67. [PubMed: 19001024]

7. Yusuf S, Pfeffer MA, Swedberg K, Granger CB, Held P, McMurray JJV, Michelson EL, Olofsson $\mathrm{B}$, Ostergren J. for the CHARM investigators and committees. Effects of candesartan in patients with chronic heart failure and preserved left-ventricular ejection fraction: the CHARM-Preserved Trial. Lancet. 2003; 362:777-81. [PubMed: 13678871]

8. Cleland JGF, Tendera M, Adamus J, Freemantle N, Polonski L, Taylor J. on behalf of PEP-CHF investigators. The perindopril in elderly people with chronic heart failure (PEP-CHF) study. Eur Heart J. 2006; 27:2338-45. [PubMed: 16963472]

9. Massie BM, Carson PE, McMurray JJ, Komajda M, McKelvie R, Zile MR, Anderson S, Donovan M, Iverson E, Staiger C, Ptaszynska A. for the I-PRESERVE investigators. New Engl J Med. 2008; 359:2456-67. [PubMed: 19001508]

10. Aurigemma GP, Gaasch WH. Diastolic heart failure. N Engl J Med. 2004; 351:1097-105. [PubMed: 15356307] 
-11. Lam CSP, Donal E, Kraigher-Krainer E, Ramachandran VS. Epidemiology and clinical course of heart failure with preserved ejection fraction. Eur J Heart Fail. 2011; 13:18-28. Comprehensive review of the clinical characteristics and outcomes in epidemiology, registry, and clinical trial cohorts of patients with HFpEF. [PubMed: 20685685]

12. Linzbach AJ. Heart failure from the point of view of quantitative anatomy. Am J Cardiol. 1960; 5:370-82. [PubMed: 14417346]

13. Grossman W, Jones D, McLaurin LP. Wall stress and petterns of hypertrophy in the human left ventricle. J Clin Invest. 1975; 56:56-64. [PubMed: 124746]

14. Kitzman DW, Little WC, Brubaker PH, Anderson RT, Hundley WG, Marburger CT, Brosnihan B, Morgan TM, Stewart KP. Pathophysiological characterization of isolated diastolic heart failure in comparison to systolic heart failure. JAMA. 2002; 288:2144-50. [PubMed: 12413374]

15. Melenovsky V, Borlaug BA, Rosen B, Hay I, Ferruci L, Morell CH, Lakatta EG, Najjar SS, Kass DA. Cardiovascular features of heart failure with preserved ejection fraction versus nonfailing hypertensive left ventricular hypertrophy in the urban Baltimore community: the role of atrial remodeling/dysfunction. J Am Coll Cardiol. 2007; 49:198-207. [PubMed: 17222731]

16. Von Heerebeek L, Borbely A, Niessen HWM, Bronzwaer JGF, van der Velden J, Stienen GJM, Linke WA, Laarman GJ, Paulus WJ. Myocardial structure and function differ in systolic and diastolic heart failure. Circulation. 2006; 113:1966-73. [PubMed: 16618817]

17. Zile MR, Baicu CF, Gaasch WH. Diastolic heart failure abnormalities in active relaxation and passive stiffness of the left ventricle. N Engl J Med. 2004; 350:1953-9. [PubMed: 15128895]

18. Westermann D, Kasner M, Steendijk P, Spillman F, Riad A, Weitmann K, Hoffmann W, Poller W, Pauschinger M, Schultheiss H-P, Tschope C. Role of left ventricular stiffness in heart failure with normal ejection fraction. Circulation. 2008; 117:2051-60. [PubMed: 18413502]

19. Ho JE, Gona P, Pencina MJ, Tu JV, Austin PC, Vasan RS, Kannel WB, D’Agostino RB, Lee DS, Levy D. Discriminating clinical feastures of heart failure with preserved versus reduced ejection fraction in the community. Eur Heart J. 2012; 33:1734-41. [PubMed: 22507977]

20. Lam CS, Lyass A, Kraigher-Krainer E, Massaro JM, Lee DS, Ho JE, Redfield MM, Pieske BM, Benjamin EJ, Vasan RS. Cardiac dysfunction and noncardiac dysfunction as precursors of heart failure with reduced and preserved ejection fraction in the community. Circulation. 2011; 124:2430. [PubMed: 21670229]

21. Shah SJ. Evolving approaches to the management of heart failure with preserved ejection fraction in patients with coronary artery disease. Curr Treat Options Cardiovasc Med. 2010; 12:58-75. [PubMed: 20842482]

22. Abhayaratna WP, Marwick TH, Smith WT, Becker NG. Characteristics of left ventricular diastolic dysfunction in the community: an echocardiographic survey. Heart. 2006; 92:1259-64. [PubMed: 16488928]

23. Persson H, Lonn E, Edner M, Baruch L, Lang CC, Morton JJ, Ostergren J, McKelvie RS. Diastolic dysfunction in heart failure with preserved systolic function: need for objective evidence: results from the CHARM Echocardiographic Substudy CHARMES. J Am Coll Cardiol. 2007; 49:687-94. [PubMed: 17291934]

-24. Zile MR, Gottdiener JS, Hetzel SJ, McMurray JJ, Komajda M, McKelvie R, Baicu CF, Massie $\mathrm{BM}$, Carson PE. Prevalence and significance of alterations in cardiac structure and function in patients with heart failure and a preserved ejection fraction. Circulation. 2011; 124:2491-501. The largest, most comprehensive dedicated echocardiographic study of patients with HFpEF which also related measures of cardiac structure and function to clinical outcomes in this population. [PubMed: 22064591]

25. Yip GW, Zhang Q, Xie JM, et al. Resting global and regional left ventricular contractility in patients with heart failure and normal ejection fraction: insights from speckle-tracking echocardiography. Heart. 2011; 97:287-94. [PubMed: 21193686]

26. Tan YT, Wenzelburger F, Lee E, et al. The pathophysiology of heart failure with normal ejection fraction: exercise echocardiography reveals complex abnormalities of both systolic and diastolic ventricular function involving torsion, untwist, and longitudinal motion. J Am Coll Cardiol. 2009; 54:36-46. [PubMed: 19555838] 
27. Yu CM, Zhang Q, Yip GWK, Lee PW, Kum LCC, Lam YY, Fung JWH. Diastolic and systolic asynchrony in patients with diastolic heart failure: a common but ignored condition. J Am Coll Cardiol. 2007; 49:97-105. [PubMed: 17207728]

28. Wang J, Kurrelmeyer KM, Torre-Amione G, Nagueh SF. Systolic and diastolic dyssynchrony in patients with diastolic heart failure and the effect of medical therapy. J Am Coll Cardiol. 2007; 49:88-96. [PubMed: 17207727]

29. Kurt M, Wang J, Torre-Amione G, Nagueh SF. Left atrial function in diastolic heart failure. Circ Cardiovasc Imaging. 2009; 2:10-15. [PubMed: 19808559]

30. Lam CSP, Roger VL, Rodeheffer RJ, Borlaug BA, Enders FT, Redfield MM. Pulmonary hypertension in heart failure with preserved ejection fraction: a community-based study. $\mathbf{J}$ Am Coll Cardiol. 2009; 53:1119-26. [PubMed: 19324256]

31. Kawaguchi M, Hay I, Fetics B, Kass DA. Combined ventricular systolic and arterial stiffening in patients with heart failure and preserved ejection fraction: implications for systolic and diastolic reserve limitations. Circulation. 2003; 107:714-20. [PubMed: 12578874]

32. Hykowsky MJ, Brubaker PH, John JM, Stewart KP, Morgan TM, Kitzman DW. Determinants of exercise intolerance in elderly heart failure patients with preserved ejection fraction. J Am Coll Cardiol. 2011; 58:265-74. [PubMed: 21737017]

33. Shah AM, Pfeffer MA. The many faces of heart failure with preserved ejection fraction. Nat Rev Cardiol. 2012; 9:555-6. [PubMed: 22945329]

34. Zile MR, Gaasch WH, Carroll JD, Feldman MD, Aurigemma GP, Schaer GL, Ghali JK, Liebson PR. Heart failure with a normal ejection fraction: Is measurement of diastolic function necessary to make the diagnosis of diastolic heart failure? Circulation. 2001; 104:779-82. [PubMed: 11502702]

35. Leong DP, De Pasquale CG, Selvanayagam JB. Heart failure with normal ejection fraction: The complementary roles of echocardiography and CMR imaging. J Am Coll Cardiol Img. 2010; 3:409-20.

36. Douglas PS, DeCara JM, Devereux RB, Duckworth S, Gardin JM, Jaber WA, Morehead AJ, Oh JK, Picard MH, Solomon SD, Wei K, Weissman NJ. Echocardiographic imaging in clinical trials: American Society of Echocardiography standards for echocardiography core laboratories: endorsed by the American College of Cardiology Foundation. J Am Soc Echocardiogr. 2009; 22:755-65. [PubMed: 19560654]

37. Edelmann F, Wachter R, Schmidt AG, Kraigher-Krainer E, Colantonio C, Kamke W, Duvinage A, Stahrenberg R, Durstewitz K, Loffler M, Dungen HD, Tschope C, Herrmann-Lingen C, Halle M, Hasenfuss G, Gelbrich G, Pieske B. Effect of spironolactone on diastolic function and exercise capacity in patients with heart failure with preserved ejection fraction: The ALDO-DHF randomized controlled trial. JAMA. 2013; 209:781-91. [PubMed: 23443441]

38. Lam CSP, Roger VL, Rodeheffer RJ, Bursi F, Borlaug BA, Ommen SR, Kass DA, Redfield MM. Cardiac structure and ventricular-vascular function in persons with heart failure and preserved ejection fraction from Olmsted County, Minnesota. Circulation. 2007; 115:1982-90. [PubMed: 17404159]

39. Maurer MS, Burkhoff D, Fried LP, Gottdiener J, King DL, Kitzman DW. Ventricular structure and function in hypertensive participants with heart failure and a normal ejection fraction: the Cardiovascular Health Study. J Am Coll Cardiol. 2007; 49:972-81. [PubMed: 17336721]

-40. Katz DH, Beussink L, Sauer AJ, Freed BH, Burke MA, Shah SJ. Prevalence, clinical characteristics, and outcomes associated with eccentric versus concentric left ventricular hypertrophy in heart failure with preserved ejection fraction. Am J Cardiol. 2013 Epub before print. Large, comprehensive echocardiographic study of a registry-based HFpEF cohort which evaluated the prognostic relevance of differences in ventricular geometry on clinical outcomes.

41. Solomon SD, Zile M, Pieske B, Voors A, Shah A, Kraigher-Krainer E, Shi V, Bransford T, Takeuchi M, Gong J, Lefkowitz M, Packer M, McMurray JJV. The angiotensin receptor neprilysin inhibitor LCZ696 in heart failure with preserved ejection fraction: A phase II randomizedcontrolled trial. Lancet. 2012; 380:1387-95. [PubMed: 22932717]

42. Devereux RB, Roman MJ, Liu JE, Welty TK, Lee E, Rodeheffer R, Fabsitz RR, Howard BV. Congestive heart failure despite normal left ventricular systolic function in a population-based sample: The Strong Heart Study. Am J Cardiol. 2000; 86:1090-6. [PubMed: 11074205] 
43. He KL, Burkhoff D, Leng WX, Liang ZR, Fan L, Wang J, Maurer MS. Comparison of ventricular structure and function in Chinese patients with heart failure and ejection fractions $>55 \%$ versus $40 \%$ to $55 \%$ versus $<40 \%$. Am J Cardiol. 2009; 103:845-51. [PubMed: 19268743]

44. Santhanakrishnan R, Ng TP, Cameron VA, Gamble GD, Ling LH, Sim D, Leong GKT, Yeo PSD, Ong HY, Jaufeerally F, Wong RCC, Chai P, Low AF, Lund M, Devlin G, Troughton R, Richards AM, Doughty RN, Lam CSP. The Singapore Heart Failure Outcomes and Phenotypes (SHOP) study and Prospective Evaluation of Outcomes in Patients with Heart Failure with Preserved Left Ventricular Ejection Fraction (PEOPLE) study: Rationale and design. J Cardiac Fail. 2013; 19:156-62.

45. Yancy CW. Heart failure in African Americans: pathophysiology and treatment. J Card Fail. 2003; 9:s210-5. [PubMed: 14583891]

46. Bahrami H, Kronmal R, Bluemke DA, Olson J, Shea S, Liu K, Burke GL, Lina JAC. Difference in the incidence of congestive heart failure by ethnicity: the Multi-Ethnic Study of Atherosclerosis. Arch Intern Med. 2008; 168:2138-45. [PubMed: 18955644]

47. East MA, Peterson ED, Shaw LK, Gattis WA, O'Connor CM. Racial differences in the outcomes of patients with diastolic heart failure. Am Heart J. 2004; 148:151-6. [PubMed: 15215805]

48. Lorber R, Gidding SS, Daviglus ML, Colangelo LA, Liu K, Gardin JM. Influence of systolic blood pressure and body mass index on left ventricular structure in healthy African-American and white young adults: the CARDIA study. J Am Coll Cardiol. 2003; 41:955-60. [PubMed: 12651040]

49. Sharp A, Tapp R, Francis DP, Thom SAM, Hughes AD, Stanton AV, Zambanini A, Chaturvedi N, Byrd S, Poulter NR, Sever PS, Mayet J. J Am Coll Cardiol. 2008; 52:1015-21. [PubMed: 18786484]

50. Kizer JR, Arnett DK, Bella JN, Paranicas M, Rao DC, Province MA, Oberman A, Kitzman DW, Hopkins PN, Liu JE, Devereux. Differences in left ventricular structure between black and white hypertensive adults: the Hypertension Genetic Epidemiology Network study. Hypertension. 2004; 43:1182-8. [PubMed: 15123573]

51. Drazner MH, Dries DL, Peshock RM, Cooper RS, Klassen C, Kazi F, Willett D, Victor RG. Left ventricular hypertrophy is more prevalent in blacks than whites in the general population: the Dallas Heart Study. Hypertension. 2005; 46:124-9. [PubMed: 15939807]

52. Gupta DK, Shah AM, Castagno D, Takeuchi M, Loehr LR, Fox ER, Butler KR, Mosley TH, Kitzman DW, Solomon SD. Heart failure with preserved ejection fraction in African Americans: the ARIC (Atherosclerosis Risk in Communities) study. J Am Coll Cardiol HF. 2013; 1:156-63.

53. Lester SJ, Tajik AJ, Nishimura RA, Oh JK, Khandheria BK, Seward JB. Unlocking the mysteries of diastolic function: Deciphering the Rosetta stone 10 years later. J Am Coll Cardiol. 2008; 51:679-89. [PubMed: 18279730]

54. Fouad FM, Slominiski JM, Tarazi RC. Left ventricular diastolic function in hypertension: relation to left ventricular mass and systolic function. J Am Coll Cardiol. 1984; 3:1500-6. [PubMed: 6232306]

55. Aurigemma GP, Silver KH, Priest MA, Gaasch WH. Geometric changes allow normal ejection fraction despite depressed myocardial shortening in hypertensive left ventricular hypertrophy. $\mathrm{J}$ Am Coll Cardiol. 1995; 26:195-202. [PubMed: 7797752]

56. Aurigemma GP, Gaasch WH, McLaughlin M, McGinn R, Sweeney A, Meyer TE. Reduced left ventricular systolic pump performance and depressed myocardial contractile function in patients 65 years of age with normal ejection fraction and a high relative wall thickness. Am J Cardiol. 1995; 76:702-5. [PubMed: 7572629]

57. Palmieri V, Wachtell K, Gerdts E, Bella JN, Papademetriou V, Tuxen C, Nieminen MS, Dahlof B, de Simone G, Devereux RB. Left ventricular function and hemodynamic features of inappropriate left ventricular hypertrophy in patients with systemic hypertension: the LIFE study. Am Heart J. 2001; 141:784-91. [PubMed: 11320367]

58. Kuznetsova T, Herbots L, Richart T, D’hooge J, Thijs L, Fagard RH, Herregods M-C, Staessen JA. Left ventricular strain and strain rate in a general population. Eur Heart J. 2008; 29:2014-23. [PubMed: 18583396]

59. Mizuguchi Y, Oishi Y, Miyoshi H, Iuchi A, Nagase N, Oki T. The functional role of longitudinal, circumferential, and radial myocardial deformation for regulating the early impairment of left 
ventricular contraction and relaxation in patients with cardiovascular risk factors: A study with two-dimensional strain imaging. J Am Soc Echocardiogr. 2008; 21:1138-1144. [PubMed: 18926389]

60. Fang ZY, Leano R, Marwick TH. Relationship between longitudinal and radial contractility in subclinical diabetic heart disease. Clin Sci (London). 2004; 106:53-60. [PubMed: 12924982]

61. Carasso S, Cohen O, Mutlak D, Adler Z, Lessick J, Reisner SA. Differential effects of afterload on left ventricular long- and short-axis function: insights from a clinical model of patients with aortic valve stenosis undergoing aortic valve replacement. Am Heart J. 2009; 158:540-5. [PubMed: 19781412]

62. Zornoff LAM, Skali H, Pfeffer MA, St John Sutton M, Rouleau JL, Lamas GA, Plappert T, Rouleau JR, Moye LA, Lewis SJ, Braunwald E, Solomon SD. Right ventricular dysfunction and risk of heart failure and mortality after myocardial infarction. J Am Coll Cardiol. 2002; 39:14501455. [PubMed: 11985906]

63. Field ME, Solomon SD, Lewis EF, Kramer DB, Baughman KL, Stevenson LW, Tedrow EB. Right ventricular dysfunction and adverse outcome in patients with advanced heart failure. J Card Fail. 2006; 12:616-620. [PubMed: 17045180]

64. D’Alonzo GE, Barst RJ, Ayres AM, Bergofsky EH, Brundage BH, Detre KM, Fishman AP, Goldring RM, Groves BM, Kernis JT, Levy PS, Pietra GG, Reid LM, Reeves JT, Rich S, Vreim $\mathrm{CE}$, Williams GW, Wu M. Survival in patients with primary pulmonary hypertension. Annals of Internal Medicine. 1991; 115:343-9. [PubMed: 1863023]

65. Klapholz M, Maurer M, Lowe AM, Messineo F, Meisner JS, Mitchell J, Kalman J, Phillips RA, Steingart R, Brown EJ, Berkowitz R, Moskowitz R, Soni A, Mancini D, Bijou R, Sehhat K, Varshneya N, Kukin M, Katz SD, Sleeper LA, Le Jemtel TH. Hospitalization for heart failure in the presence of a normal left ventricular ejection fraction: Results of the New York Heart Failure Registry. J Am Coll Cardiol. 2004; 43:1432-8. [PubMed: 15093880]

66. Tribouilloy C, Rusinaru D, Mahjoub H, Souliere V, Levy F, Peltier M, Slama M, Massy Z. Prognosis of heart failure with preserved ejection fraction: A 5 year prospective population-based study. Eur Heart J. 2008; 29:339-47. [PubMed: 18156618]

67. Redfield MM, Chen HH, Borlaug BA, Semigran MJ, Lee KL, Lewis G, LeWinter MM, Rouleau JL, Bull DA, Mann DL, Deswal A, Stevenson LW, Givertz MM, Ofili EO, O'Connor CM, Felker GM, Goldsmith SR, Bart BA, McNulty SE, Ibarra JC, Lin G, Oh JK, Patel MR, Kim RJ, Tracy RP, Velazquez EJ, Anstrom KJ, Hernandez AF, Mascette AM, Braunwald E. Effect of phosphodiesterase-5 inhibition on exercise capacity and clinical status in heart failure with preserved ejection fraction: A randomized clinical trial. JAMA. 2013; 309:1268-77. [PubMed: 23478662] 


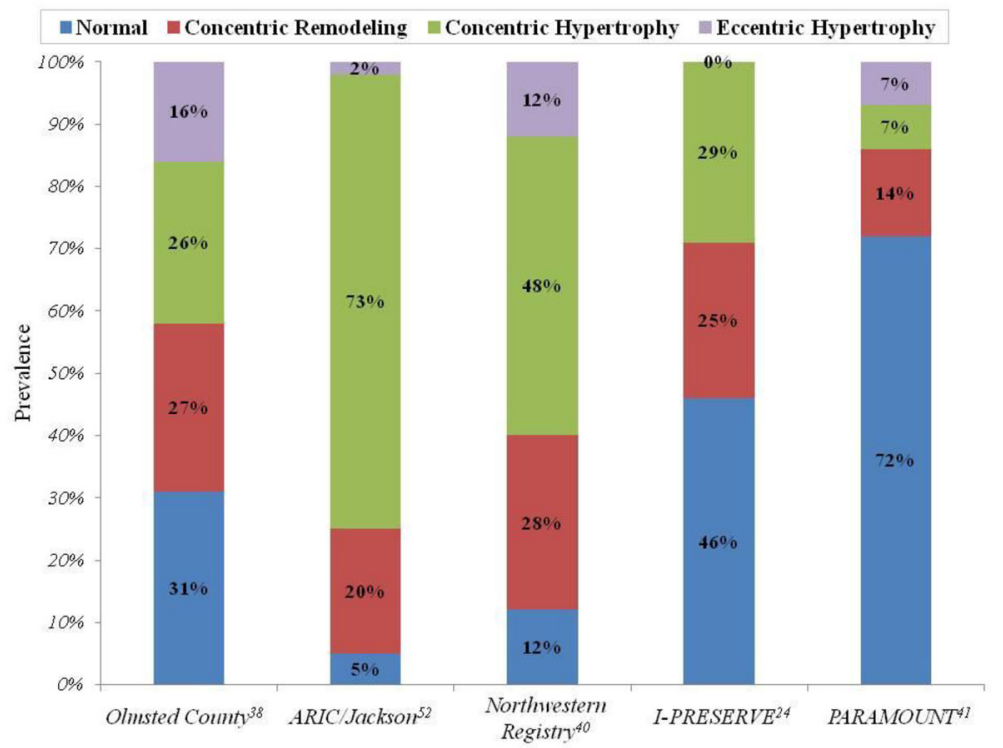

Figure 1.

Prevalence of ventricular geometric patterns in select epidemiology, registry, and clinical trial HFpEF cohorts demonstrating the heterogeneity in ventricular remodeling found in this syndrome. 


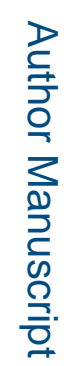

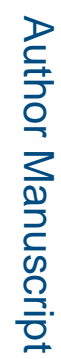

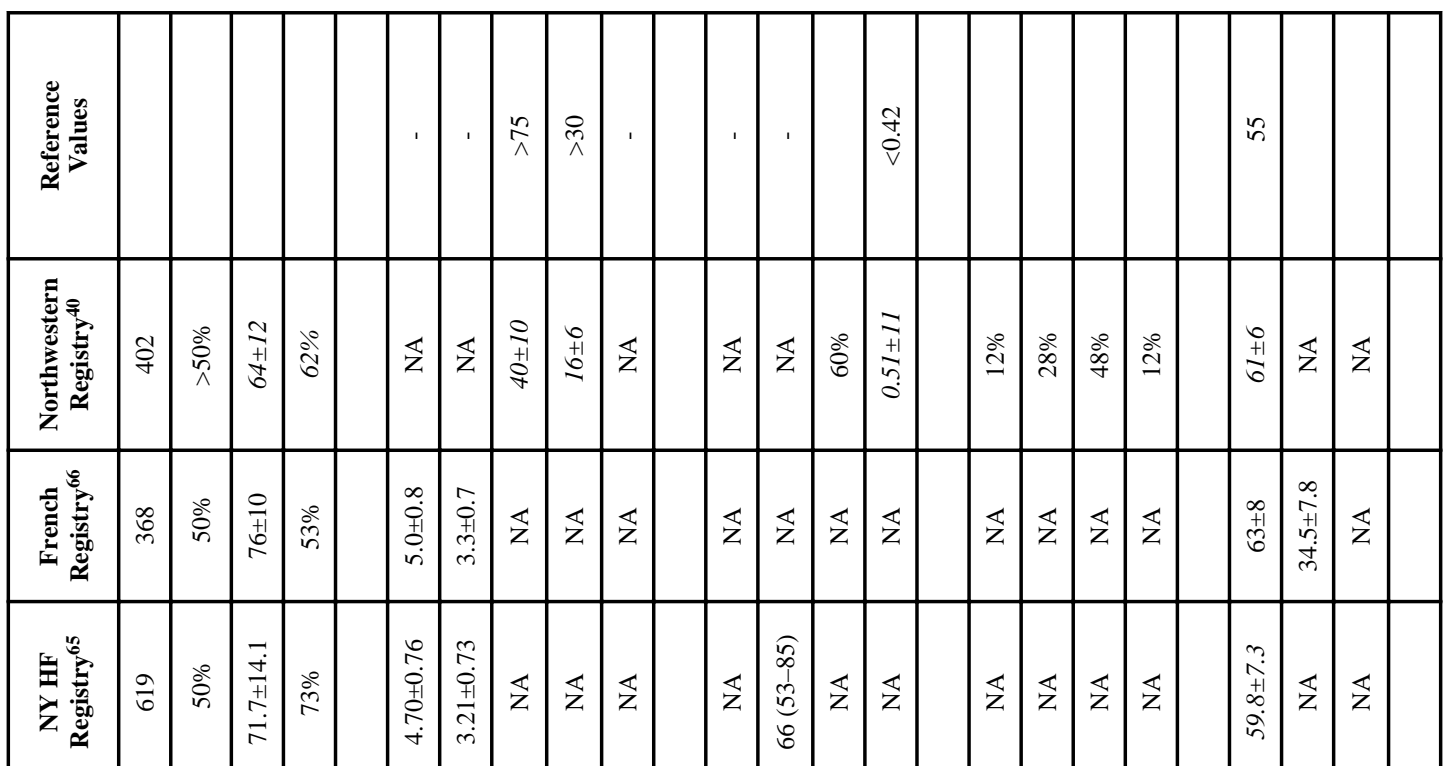

\begin{tabular}{|c|c|c|c|c|c|c|c|c|c|c|c|c|c|c|c|c|c|c|c|c|c|c|c|}
\hline 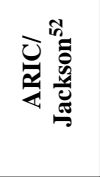 & 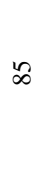 & 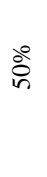 & $\begin{array}{l}6 \\
0 \\
i \\
0 \\
0 \\
0\end{array}$ & $\stackrel{\circ}{\infty}$ & & $\begin{array}{l}\underset{+}{+} \\
\stackrel{+}{+} \\
\stackrel{+}{+}\end{array}$ & 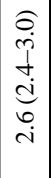 & $\overleftrightarrow{z}$ & 艺 & 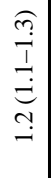 & 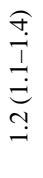 & 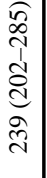 & $\overleftrightarrow{z}$ & $\stackrel{\circ}{i}$ & 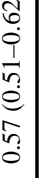 & $\ddot{\circ}$ & ఫे & $\stackrel{\circ}{\check{2}}$ & & $\begin{array}{l}n \\
\hat{1} \\
0 \\
6 \\
6\end{array}$ & $\begin{array}{l}\frac{f}{f} \\
\frac{0}{0} \\
\text { ch }\end{array}$ & $\overleftrightarrow{z}$ & \\
\hline 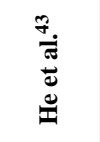 & $\stackrel{\infty}{\underset{\sim}{\sim}}$ & 离 & 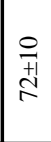 & $\begin{array}{l}80 \\
i b\end{array}$ & & $\begin{array}{l}0 \\
\dot{0} \\
\stackrel{+1}{+1} \\
\dot{+}\end{array}$ & \begin{tabular}{|l}
$n$ \\
0 \\
+1 \\
$m$ \\
$m$
\end{tabular} & $\mid \begin{array}{l}0 \\
+1 \\
0 \\
n\end{array}$ & $\begin{array}{l}\infty \\
\text { i } \\
\text { ते }\end{array}$ & $\begin{array}{l}\tilde{O} \\
0 \\
+1 \\
\end{array}$ & 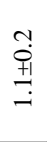 & 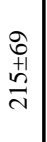 & 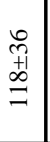 & $\overleftrightarrow{z}$ & $\mathbb{z}$ & $\mathbb{z}$ & $\mathbb{z}$ & z & & 等 & $\begin{array}{l}+ \\
+ \\
+\end{array}$ & $\begin{array}{l}\text { †े } \\
\text { mे }\end{array}$ & \\
\hline 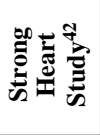 & in & 突 & $\begin{array}{l}\text { 辛 } \\
\text { +1 }\end{array}$ & $\stackrel{\circ}{\circ}$ & & $\begin{array}{l}0 \\
0 \\
0 \\
+1 \\
\dot{0} \\
\dot{0}\end{array}$ & $\mathbb{z}$ & $\mathbb{z}$ & $\overleftrightarrow{z}$ & 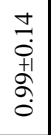 & 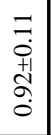 & 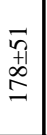 & 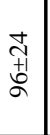 & $\overleftrightarrow{z}$ & 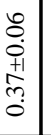 & $\overleftrightarrow{z}$ & $\overleftrightarrow{z}$ & $\overleftrightarrow{z}$ & & 利 & $\overleftrightarrow{z}$ & $\overleftrightarrow{z}$ & \\
\hline 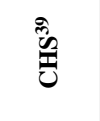 & $\underline{\underline{\sigma}}$ & $\begin{array}{l}* \\
\text { *o } \\
\text { in }\end{array}$ & 势 & $\frac{\stackrel{0}{5}}{i n}$ & & $\begin{array}{c}\infty \\
\dot{0} \\
\stackrel{+1}{n} \\
\dot{n}\end{array}$ & $\begin{array}{l}0 \\
\dot{0} \\
01 \\
0 \\
\dot{m}\end{array}$ & \begin{tabular}{l}
$\tilde{T}$ \\
\multirow{1}{1}{} \\
$\mathrm{O}$
\end{tabular} & $\begin{array}{l}0 \\
\text { +1 } \\
\text { ते }\end{array}$ & $\mathbb{z}$ & 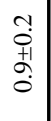 & 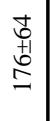 & 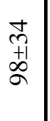 & $\overleftrightarrow{z}$ & $\begin{array}{l}7 \\
0 \\
0 \\
01 \\
0 \\
0 \\
0\end{array}$ & $\overleftrightarrow{z}$ & $\overleftrightarrow{z}$ & $\overleftrightarrow{z}$ & & 站 & 䇃 & $\frac{t}{\frac{t}{11}}$ & \\
\hline 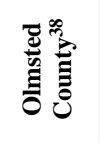 & 寺 & 离 & $\begin{array}{l}\hat{\sigma} \\
\hat{i} \\
\text { ḋ } \\
\text { ह }\end{array}$ & 总 & & $\mathbb{z}$ & $\vec{z}$ & 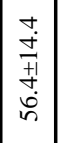 & $\overleftrightarrow{z}$ & $\mathbb{z}$ & $\mathbb{z}$ & $\begin{array}{l}\overrightarrow{\dot{c}} \\
\dot{0} \\
+1 \\
\dot{0} \\
\dot{\pi}\end{array}$ & 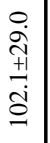 & ఫั & $\begin{array}{l}0 \\
\dot{+1} \\
\text { +1 } \\
\text { in } \\
0 \\
0\end{array}$ & $\frac{\circ}{m}$ & $\stackrel{\circ}{\stackrel{\circ}{\circ}}$ & క్రి & & $\begin{array}{l}\text { II } \\
\text { In }\end{array}$ & $\overleftrightarrow{z}$ & 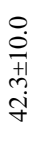 & \\
\hline & $z$ & 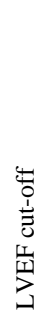 & 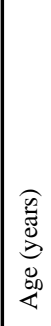 & $\begin{array}{l}\frac{0}{\tilde{\Xi}} \\
\text { ज्ञ } \\
\text { w }\end{array}$ & 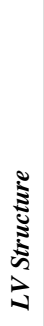 & 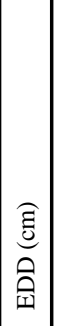 & 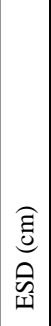 & 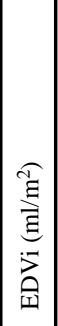 & 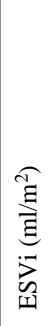 & 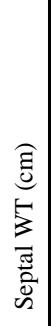 & 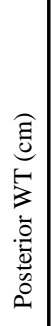 & 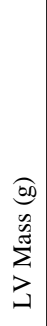 & 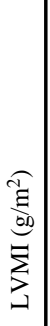 & 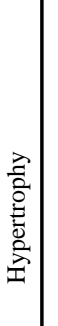 & $\sum_{2}^{5}$ & 愛 & 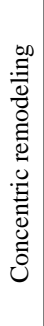 & 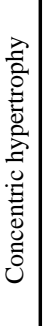 & & $\frac{8}{5}$ & 鹿 & 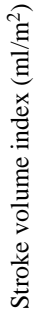 & 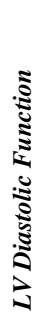 \\
\hline
\end{tabular}




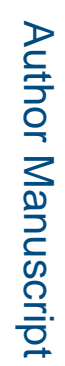

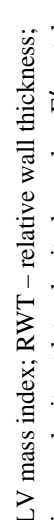

훙

\begin{tabular}{|c|c|c|c|c|c|c|c|c|c|c|c|}
\hline 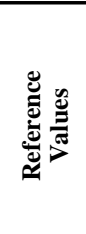 & $\begin{array}{l}\text { ते } \\
\text { }\end{array}$ & वे & & 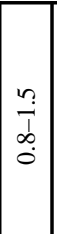 & 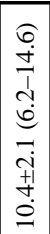 & 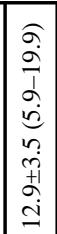 & 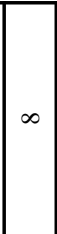 & $\not$ & & & \\
\hline 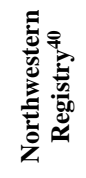 & 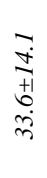 & $\overleftrightarrow{z}$ & $\overleftrightarrow{z}$ & $\begin{array}{l}\hat{0} \\
+1 \\
\stackrel{+}{-}\end{array}$ & $\begin{array}{l}n \\
i \\
+1 \\
+1 \\
r \\
\end{array}$ & $\mid \begin{array}{c}\hat{\sigma} \\
+\overrightarrow{+} \\
\tilde{\alpha}\end{array}$ & $\mid \begin{array}{c}\infty \\
+1 \\
\stackrel{+1}{=}\end{array}$ & $\overleftrightarrow{z}$ & $\overleftrightarrow{z}$ & $\overleftrightarrow{z}$ & \\
\hline 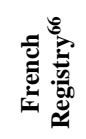 & $\overleftrightarrow{z}$ & $\overleftrightarrow{z}$ & $\begin{array}{l}\hat{\sigma} \\
\dot{+1} \\
\dot{+}\end{array}$ & $\overleftrightarrow{z}$ & $\mathbb{z}$ & $\overleftrightarrow{z}$ & $\overleftrightarrow{z}$ & $\mathbb{z}$ & $\overleftrightarrow{z}$ & $\overleftrightarrow{z}$ & \\
\hline 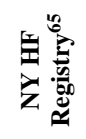 & $\overleftrightarrow{z}$ & $\overleftrightarrow{z}$ & & $\mathbb{z}$ & $\overleftrightarrow{z}$ & $\mathbb{z}$ & $\mathbb{z}$ & $\mathbb{z}$ & $\mathbb{z}$ & 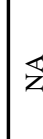 & \\
\hline 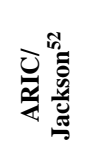 & $\mathbb{z}$ & $\overleftrightarrow{z}$ & $\mid$\begin{tabular}{c|}
$\widehat{\alpha}$ \\
$\dot{j}$ \\
$\dot{1}$ \\
$\dot{d}$ \\
$\dot{j}$ \\
$\dot{m}$
\end{tabular} & 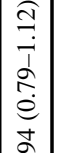 & $\overleftrightarrow{z}$ & $\mathbb{z}$ & $\overleftrightarrow{z}$ & $\mathbb{z}$ & 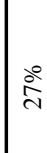 & $\mathbb{z}$ & \\
\hline
\end{tabular}

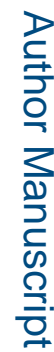

\begin{tabular}{|c|c|c|c|c|c|c|c|c|c|c|c|c|}
\hline 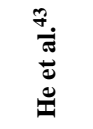 & $\overleftrightarrow{z}$ & $\overleftrightarrow{z}$ & $\begin{array}{l}n \\
\text { ñ } \\
0 \\
\dot{m}\end{array}$ & \begin{tabular}{|l|}
$\infty$ \\
$\dot{+}$ \\
+1 \\
\\
-
\end{tabular} & $\begin{array}{c}T_{1} \\
\infty\end{array}$ & $\overleftrightarrow{z}$ & 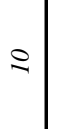 & $\overleftrightarrow{z}$ & $\overleftrightarrow{z}$ & $\overleftrightarrow{z}$ & & $\mathbb{z}$ \\
\hline 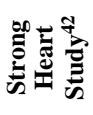 & $\overleftrightarrow{z}$ & $\overleftrightarrow{z}$ & $\overleftrightarrow{z}$ & 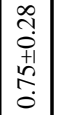 & $\overleftrightarrow{z}$ & $\overleftrightarrow{z}$ & $\overleftrightarrow{z}$ & $\overleftrightarrow{\mathrm{z}}$ & $\overleftrightarrow{z}$ & z & & $\mathbb{z}$ \\
\hline 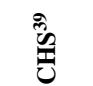 & $\overleftrightarrow{z}$ & $\overleftrightarrow{z}$ & $\mathbb{z}$ & 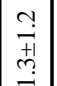 & $\overleftrightarrow{z}$ & $\overleftrightarrow{z}$ & $\mathbb{z}$ & $\overleftrightarrow{z}$ & $\overleftrightarrow{z}$ & $\overleftrightarrow{z}$ & & $\mathbb{z}$ \\
\hline 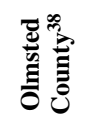 & $\overleftrightarrow{z}$ & $\overleftrightarrow{z}$ & $\overleftrightarrow{z}$ & $\begin{array}{l}0 \\
\dot{0} \\
+1 \\
\stackrel{+1}{9} \\
\end{array}$ & $\begin{array}{l}\vec{i} \\
\overrightarrow{+} \\
\dot{0} \\
\dot{\sigma}\end{array}$ & $\overleftrightarrow{z}$ & 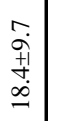 & $\mathbb{z}$ & $\mathbb{z}$ & $\overleftrightarrow{z}$ & & $\overleftarrow{z}$ \\
\hline & 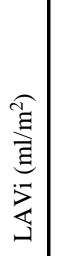 & 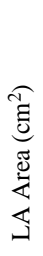 & 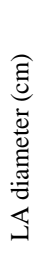 & 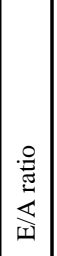 & 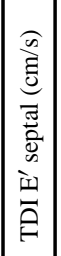 & 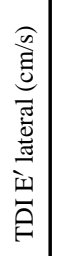 & 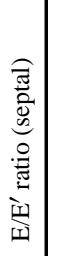 & 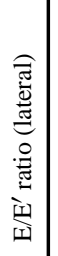 & 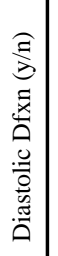 & 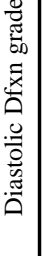 & 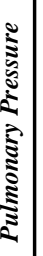 & 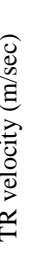 \\
\hline
\end{tabular}

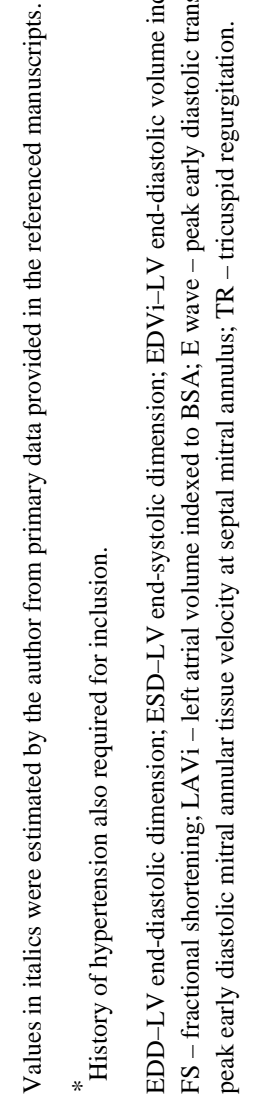


를

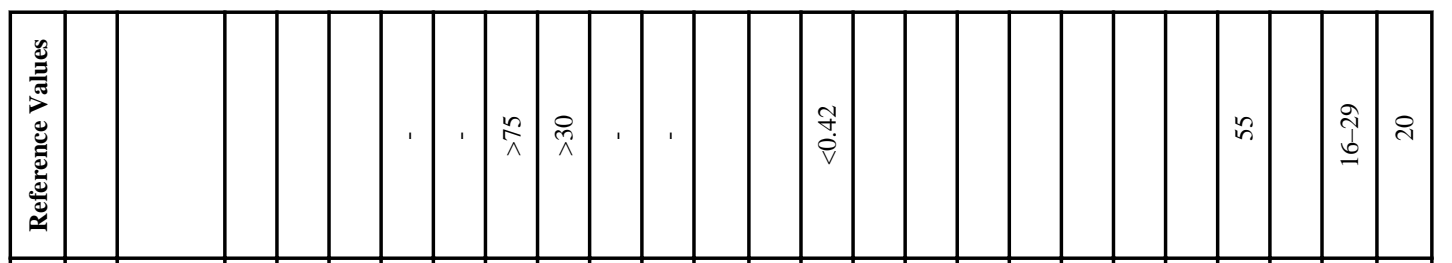

D

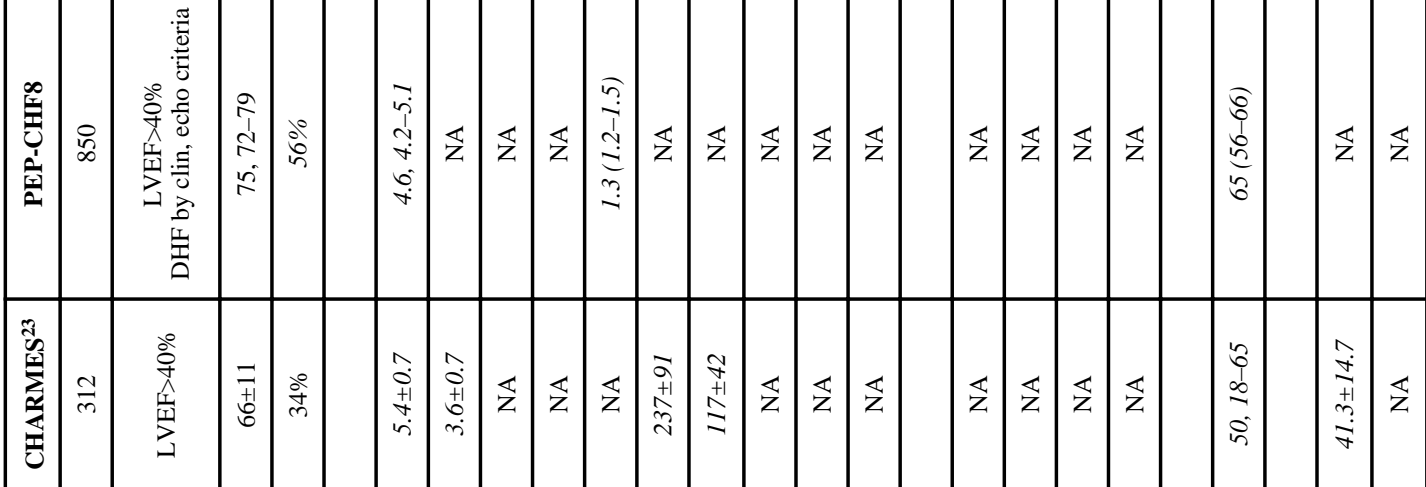

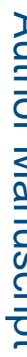

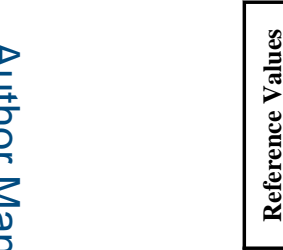

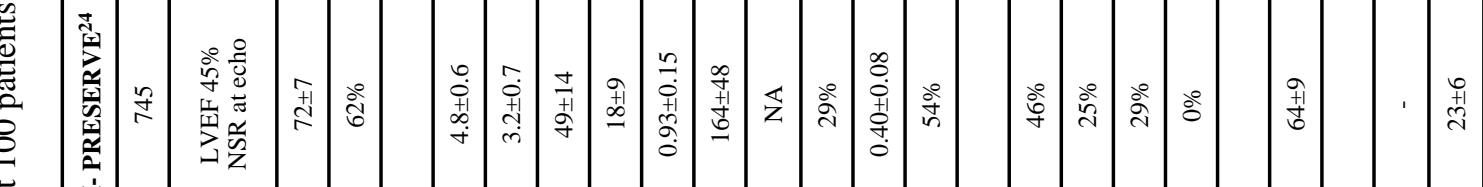

竞

$-$

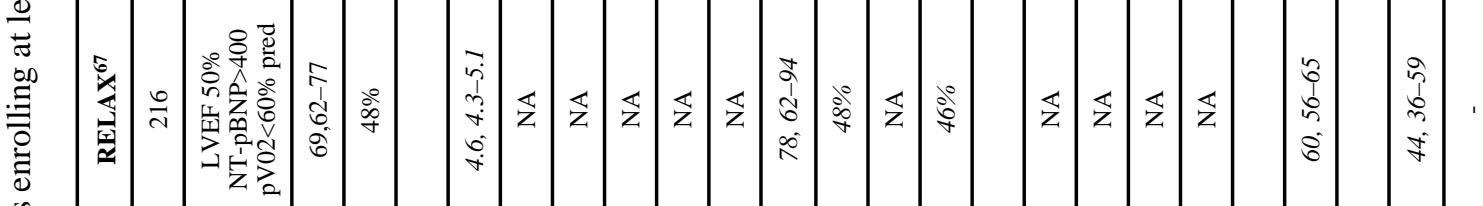

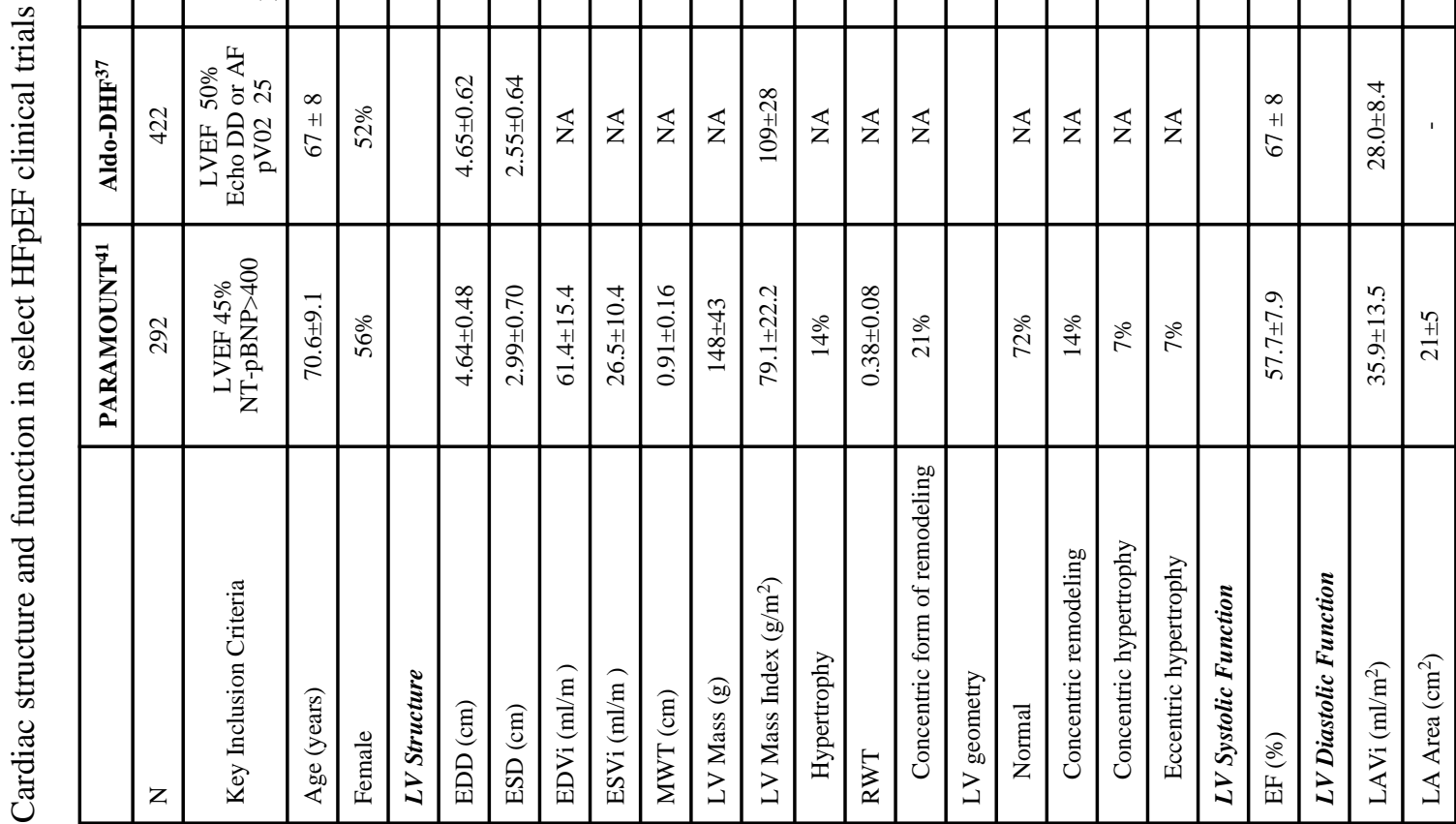

로을

Curr Heart Fail Rep. Author manuscript; available in PMC 2015 June 15. 


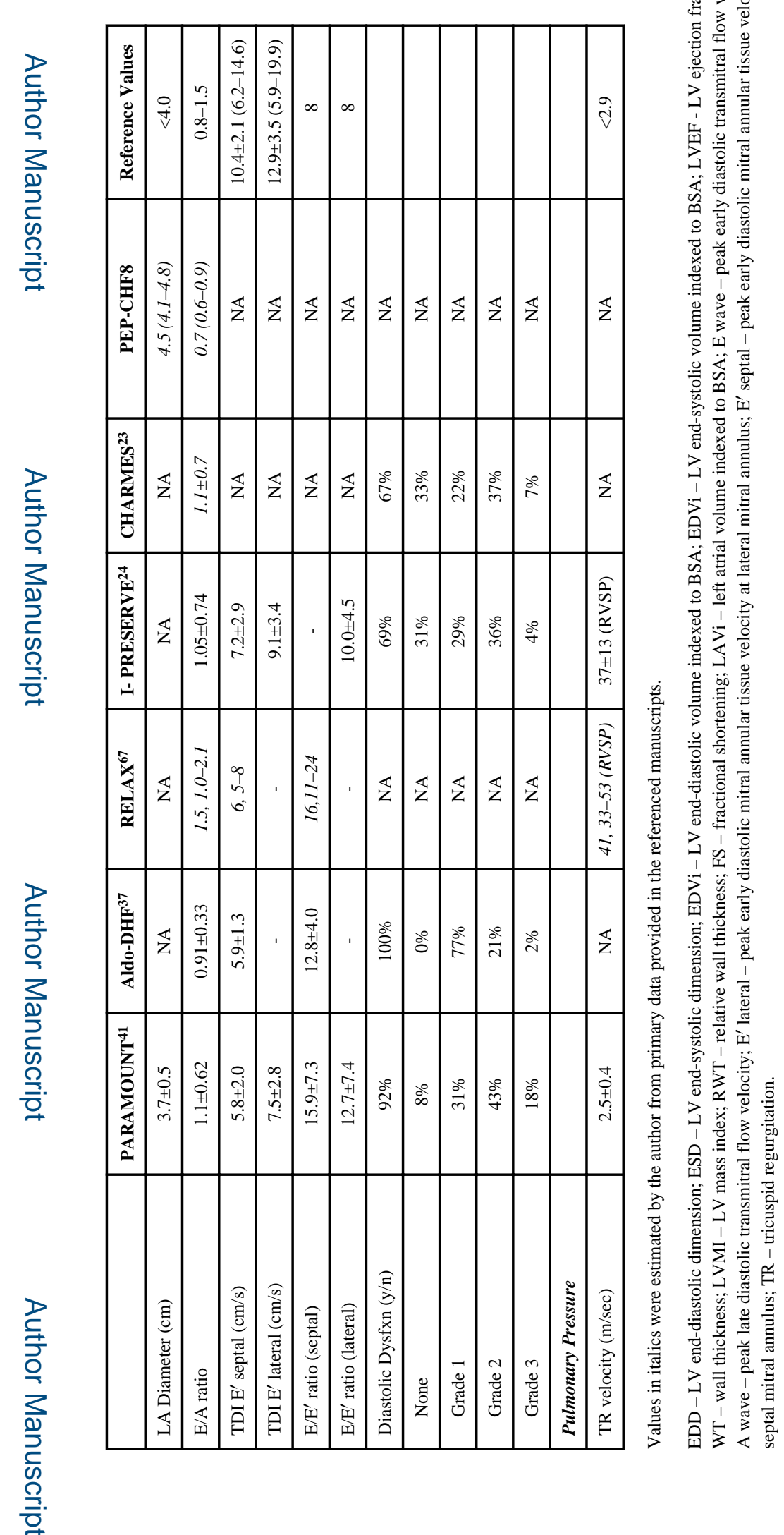

Curr Heart Fail Rep. Author manuscript; available in PMC 2015 June 15. 